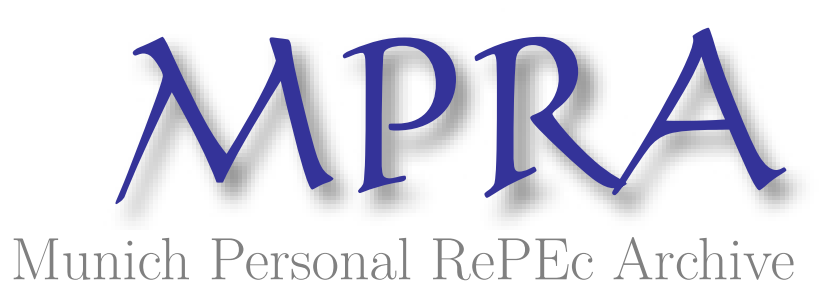

\title{
Bitcoin Mission Statement. Or What does it mean Sharing Economy and Distributed Trust?
}

Kosten, Dmitri

15 November 2015

Online at https://mpra.ub.uni-muenchen.de/73568/

MPRA Paper No. 73568, posted 12 Sep 2016 07:37 UTC 


\title{
Bitcoin Mission Statement
}

\author{
Or \\ What does it mean Sharing Economy and Distributed Trust?
}

\author{
Dmitri Kosten $^{\S}$
}

\begin{abstract}
Technological advancements in the means of production are the driving force behind the changes in the prevailing system of socio-economic relations. Feudalism was transformed into capitalism as a result of such advancements. While man obtained physical freedom, the financial freedom remained under the control of the centralized authority.

A deep level of collaboration is required to attain the next level of productivity provided by new technological advancements. However, the present system with a centralized control of governance and finance appears to constrain and restrain the value producing economy. This constriction becomes especially evident when the business environment requires collaboration to create, as it underlines the inherent conflict of centralized control. The most recent tech sector innovations, such as smart contracts and cryptocurrencies, are poised to disrupt the system of centralized control. The removal of a centralized authority from the position of control will change the fabric of the society to reflect the mesh network of shared resources. The society will transform to the new form of socio-economic relations - the era of CryptoSocialism.
\end{abstract}

\section{Summary}

The biggest achievement and value proposition of Blockchain and Bitcoin technology is their ability to give the powers of governance and finance to the people via peer-to-peer technology. It shifts power from centralized authorities to the power of the network - the power of masses. When Feudalism transitioned to Capitalism, the power of governance was given to the masses. Yet, the power of finance remained a centralized function ${ }^{\mathrm{i}}$.

For the first time, the Blockchain technological innovation has given society the option of decentralizing the function of finance and control of the financial industry. This also creates a transparent mechanism for jointly owning public assets and managing the regulations of public affairs without intermediaries. Many roles of the government will change as the result of the decentralization of the function of finance. Some roles will be automated, some simplified, and some retired. The prevailing socio-economic framework will no longer fit the new ecosystem of relations and changes will be required. Is this the beginning of a transition from Capitalism to another state - the state of Crypto-Socialism?

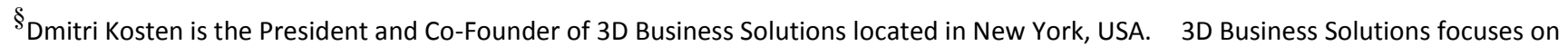
Blockchain technology as a paradigm shift that brings innovation to the Insurance and Financial Services industry. Our vision outlines the Insurance Industry ecosystem using Blockchain technology, smart contracts, and peer-to-peer architecture. Our research validates that Blockchain technology provides an opportunity to significantly improve business model.
} 

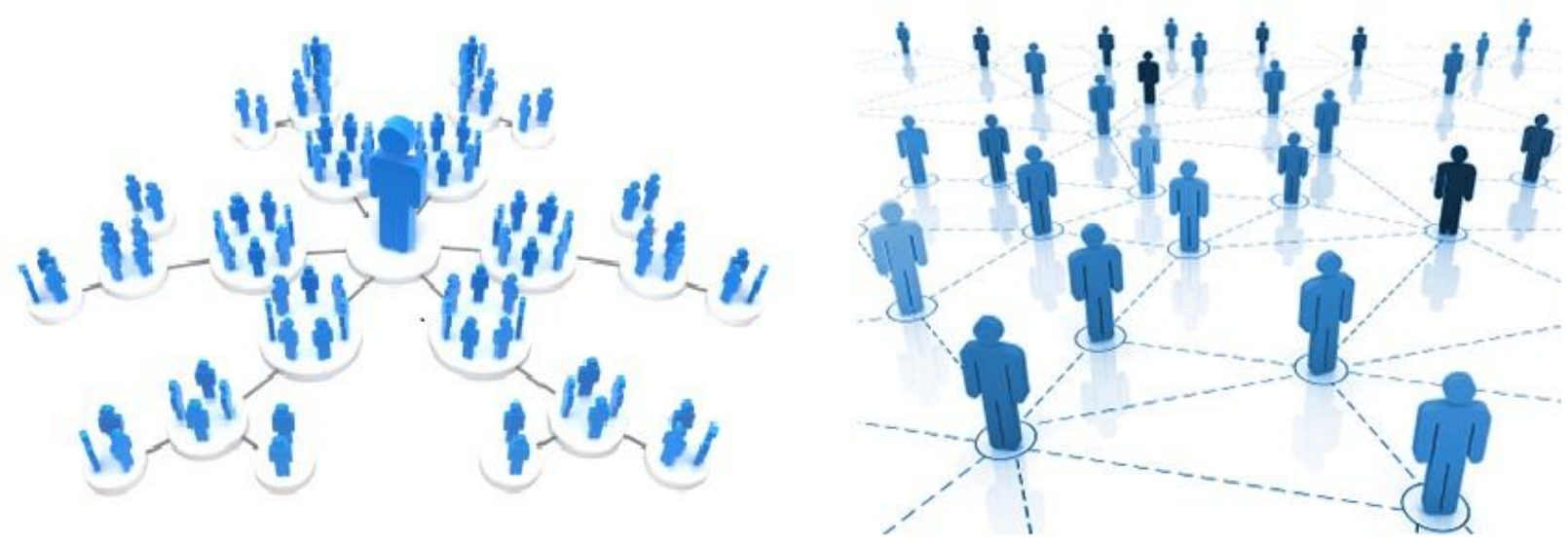

The social impact of this change can be compared to the social effect of abolition of slavery, and the technological impact can be compared to the influence of the invention the combustion engine had. The economic impact seems likely to move society towards a new structure of socio-economic relationships, possibly what Marx described as socialism or some form of it.

Blockchain technology and its adaptation will go through several phases. First, it will disrupt the financial sector. Then, it will propagate trough the value-creating sector. Finally, it will force change on socio-economic institutions to become more reflective of a new form of social organization.

This technology is in its formative stage today. However, its influence is already being felt in the financial industry and an increased reliance on it seems to be a natural course of our socio-economic evolution.

\section{Introduction}

Blockchain technologies, and bitcoin as its first practical application, continue to thrive and grow at an unprecedented rate. Why are masses of people and organizations of all stripes continuing to join this un-endorsed ecosystem? The answer is simple - it makes better sense, socially and economically. For some it is an "aha" moment and for some it is simply a matter of following their intuition.

It is not an easy task to understand the concept of the Blockchain at first, and then grasp its implications. Deep subject matter expertise is required in multiple disciplines such as Computer Science, Information Technologies, Economics, Finance, and possibly others. Yet, once the concepts are understood and the implications are grasped, the effect can be compared to the discovery of the third dimension in a two dimensional world. What previously was viewed as a sufficient form of operation, the new model reveals to be flat and lacking perspective.

The single most important flaw of the financial system today is its ability to print fiat. Archimedes once said "Give me the lever and place to stand, and I will move the world." The same can be paraphrased today about fiat: "Give me the printer and the country to print, and I will buy the world."

The economics textbooks state that the impact of printing has a velocity of propagation through the economic pipeline. This puts at a predefined competitive disadvantage entities that are furthest away from the center of the money supply. The centralized printing discriminates with a higher burden those who are further away from the center of the money supply on the chain of economic activity. This begs the question: "Is this a designed feature, or is it an unintended economic consequence?" 

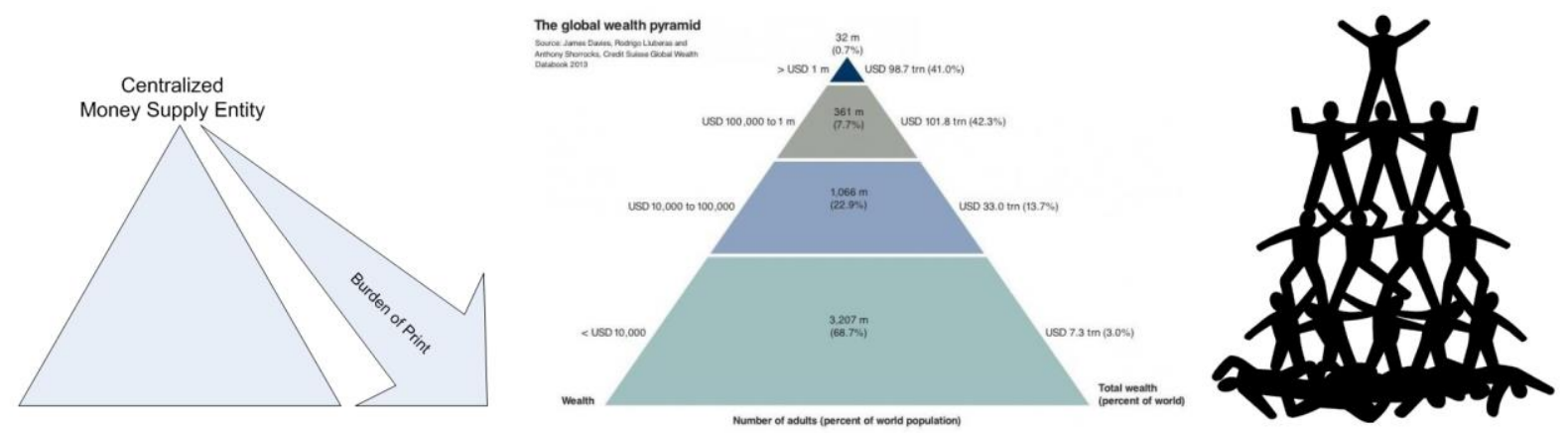

When comparing the central bank driven system with a decentralized crypto-currency alternative, it becomes apparent that centralized system sets the framework where the order of access to freshly printed cash in the chain of economic activities make significant, if not primary, the difference in the formula of competitive advantage. Businesses with a spot "closest to the king" get rewarded with greater economic rents. The last spot in the order carries the full burden of devaluation.

This becomes an especially detrimental trend over a statistically significant period of time. The competition for creating better economic value eventually gets replaced with the competition for the "seat higher up on the ladder." Direct evidence of this is the latest surge of crony-capitalism business models in all corners of the world. ${ }^{\text {ii }}$

The decentralized principle of bitcoin is poised to end this detrimental trend and restore equilibrium to market relationships with its re-emphasis on value creation. When this shift to a decentralized crypto-currency network gains critical mass, the hierarchical order of access to cash will be replaced with the principles of a mesh network and thus, will reflect the principles of social and democratic co-existence to a far greater degree. ${ }^{\text {iii }}$
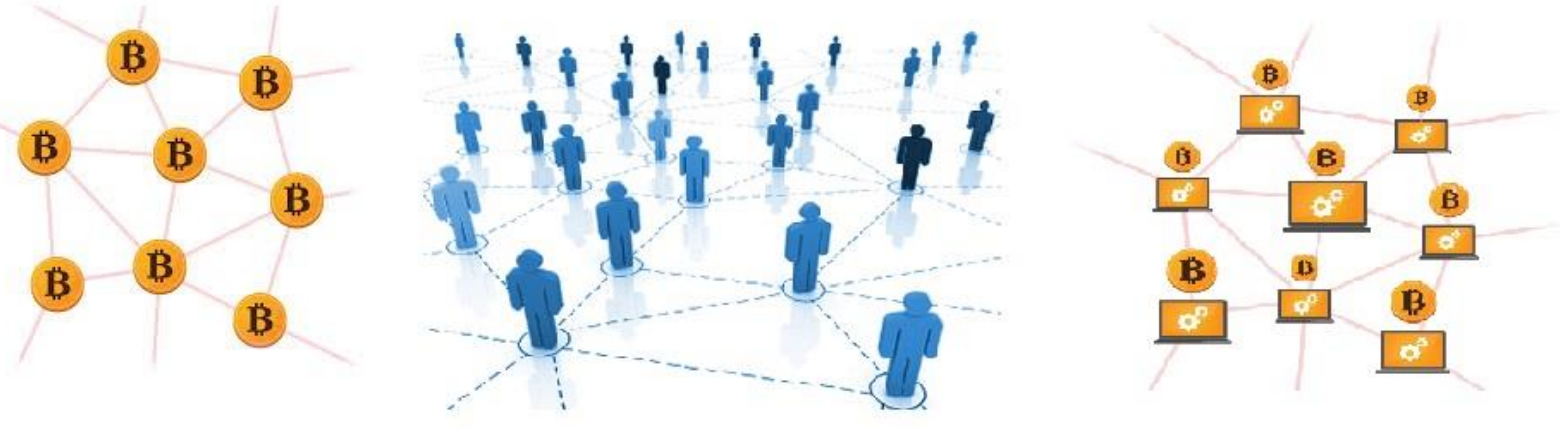

This change will trigger the transformation of the socio-economic structure of society in many ways - some aspects of this change are quite difficult to envision.

\section{Transformation}

The technological simplicity and "permissionless" principles of the decentralized model, together with substantially lower costs of doing business will first cripple the artificial grip of the banking industry on many high-margin financial services like money transmission, financial underwriting, etc. Those services are already getting replaced with cost-effective decentralized solutions and making it economically feasible to deliver financial services to all corners of the world, regardless of scale.

Further propagation of financial decentralization will make certain centrally scheduled functions obsolete, and will make impossible the abuses inherent into today's centralized trust based financial system, such as: LIBOR collusions, naked shorts, front running, and others. Because the design itself of a trustless and decentralized system re-unites trade and settlement into one transaction ${ }^{\text {iv }}$, such systemic abuses will be automatically precluded. This will stop the process of siphoning net worth from the system at the level of event orchestration ${ }^{v}$, which is

$$
3 \mid \mathrm{P} \text { a g e }
$$


believed to be one of the major sources of economic inequalities. Over time, the market forces will re-distribute economic values more evenly among all market participants. This change will facilitate a more sustainable market growth for years to come. ${ }^{\mathrm{vi}}$

This transformation over time will lead to more proportionate accumulation of wealth. The middle class will regain and expand its social influence. As a reaction to economic transformation, the social structure of society will begin to transform.

The same mechanism will halt the practice of excessive risk-taking by systemic institutions. The unlimited access to fiat combined with the too-big-to-fail policy is the most blatant example of the moral-hazard dilemma in the financial services industry today. The inability to get access to bail out funds will play the role of a natural deterrent. For example, in the absence of a centralized money supply channel the fractional reserve banking system will be significantly impaired, or may cease to exist. Because the mesh network has no single authority to replenish bank reserves in the event of a bank run or excessive risk taking, the system of fractional reserve will become impractical.

The removal of the centralized the money supply mechanism will end the "taxation through inflation" (A. Greenspan, The Objectivist, 1968) policy that is used aggressively as mechanism of transferring value to the top through devaluation of accumulation at the bottom. The decentralized money supply network (a.k.a. miners) will disrupt existing money supply channels, the role currently played by the banking industry, by default is the main economic beneficiary of the system by means fractional reserve and multiplier effect. No longer will "seat higher up on the ladder" produce competitive advantage.

Today the centralized money supply system has all the mechanisms for the total control of resource reallocation, irrespective of market conditions. The unconstrained access to fiat creates the environment where significant labor and material resources can be re-allocated at one's will. Wars and research can be funded without regard for supply and demand, taxing both sides of the equation. It also creates an environment for wasteful spending of finite natural resources. The danger of accelerating our exhaustion of resources today, when our technology has not yet been developed to fully utilize them, carries the price tag into the not so distant future. Dmitry Mendeleev, the father of chemical elements periodic table, once said that "Using oil for heating purposes, is as barbaric as using paper government bonds for sustaining the fire to keep the house warm."

\section{Money Scarcity Principle vs. Trust to Authority - History Matters}

The concept of money was well developed even before feudal times. Gold and other scarce objects played role of the money at different times. The unifying property of those objects was always scarcity. Sometimes money's material had real economic use, but most of the time it simply represented an economic status by virtue of its scarcity. Scarcity was always the single unifying property until the centralization of authority came into place. Scarcity was replaced with the trust in and reliance upon a centralized authority.

History indicates that the monetization of trade relations got centralized in feudal times. The feudal lord used to stand behind the process of money production with his reputation, wealth, military might, and promise to protect. By the social and legal framework of the times, he used to be the owner and defender of the entire economic ecosystem and trust in his authority made sense.

One of the key characteristic of feudal times was that man and property belonged to the same category - physical assets, a chattel. The lord controlled all the aspects of socio-economic relations, governance and infrastructure. The aggregate wealth of the economy translated directly into the Lord's total wealth. The lord's ownership of the whole entirety was a natural systemic deterrent from the devaluation of his economic assets to support for his social or political aspirations. Nevertheless, history preserved examples of overspending lords diluting the assets, leading to kingdom's decay, social turbulence, and often conquest by neighboring states for the purposes of exploitation. 


\section{From Feudalism to Capitalism - Emergence of Public Domain and "Elected Official's Dilemma"}

Technological advancement and the need for specialization became the driving force behind feudalism's transformation into the next form of socio-economic relations - capitalism. It began with formation of independent guilds, artisan's villages, and later got transformed into towns and cities of freed residents, under independent self-ruling governing structures.

With further technological advancements, cities and towns continued to grow and accumulate economic might, getting organized into regions and countries. The growing demand for labor free of ownership paved the way to the abolition of slavery and marked the final step in the transition of society to capitalism. The end of feudalism and the abolition of slavery ended the physical ownership of man by man.

Technological advancements brought to light that motivations and desires are better at improving man's productivity rather than enhancing his maintenance and upkeep. To attain full utilization of technological advancements and to reach qualitatively different levels of productivity, free labor was required to establish new attitude towards work. Ethics, and especially work ethics, became an integral part of the employer-employee relationships. Labor was required to develop a high level of esteem, which meant to reach to higher levels on the Maslow's pyramid of hierarchical needs. ${ }^{\text {vii }}$ The self-esteem, confidence, sense of achievement, respect of others, and respect by others became required character traits and integral parts of working relationships.

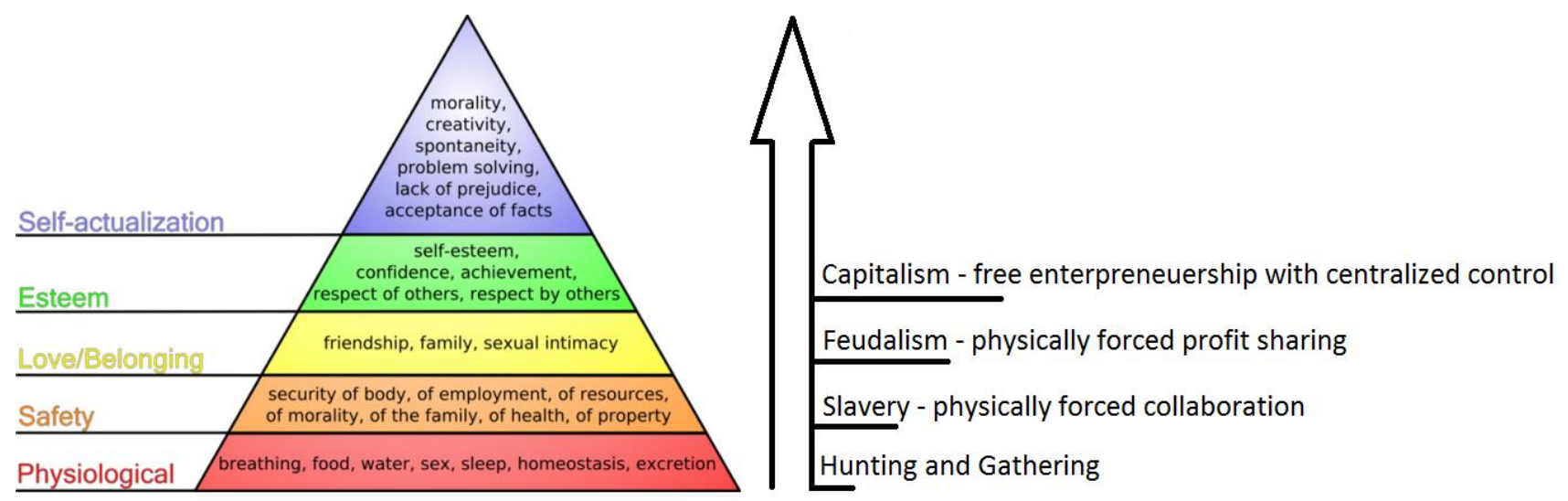

It is important to note, that it is not means of production alone, but production combined with the change in the attitude towards working relationships that made the new form of socio-economic relations superior to the existing feudal model. This new form of socio-economic relations made evident that man and property no longer shared the same characteristics, thus requiring re-classification. It becam necessary for the institution of socioeconomic relations to re-adjust itself as a result.

The new institution of socio-economic relations declared the liberation of man. Man was no longer classified as "chattel" or physical property. The principles of new socio-economic relations were re-established based on individual freedom, choice, respect, personal will, and equality.

In the same spirit of individual freedom, choice, respect, personal will, and equality, young capitalism embraced the elective form of governing public affairs. This new model placed elected officials in the position where they must manage their individual economic interests within the scope of such abstract and non-tangible concepts as public interests. The very choice of selecting the model of elective governance introduced the temptation and gave the birth to the principle of "The Elected Official's Dilemma."

The "Elected Official's Dilemma" is the concept specific to capitalism, where the conflict of public and private ownership exists. Free man, as a newly-created class in the formula of socio-economic relations, represented a 
growing force that required a layer of physical and organizational structure that had no ownership. The concept of the public sector was born as a result.

In the feudal times the lord was the owner of what is now a "public sector." The absence of "the owner" and replacement of this role with the elected individual who gets entrusted with the power of managing public assets and the public infrastructure automatically introduces the element of temptation. The elected individual is placed in a position where he is tempted to earn benefits for himself while operating assets that belong to no one specifically and in the framework of such an abstract concept as "public interests." The higher the level of governance, and the larger the constituency, the more abstract the concept of "public interests" becomes. The power of temptation grows higher with the proportion of assets under one's supervision.

What types of measures or mechanisms can society and its constituency introduce to counter such a dilemma? One option is to create layers of laws and top them up with layers of enforcement mechanisms to preclude the possibility of abuse. This option is exercised by society today.

Another option would be to remove the actual ground for temptation to a maximum degree from the system of governance, by making it systemically impossible to gain personal benefit from governing public interests. Even Plato, in The Republic, saw the need of safeguarding the public interest by limiting remuneration in the "golden" ruling class, which had as its reward the privilege of ruling itself.

Our history, and evidences, point out, the first option is not producing the desired result, regardless of the level of complexity of the laws and enforcing mechanisms. Moreover, data indicates that the system of governance continues to expand, and even becoming a burden, in some cases. Prominent economists argue that the cost of governance starts to outgrow the benefits it produces $^{\text {viii }}$.

If the second option is to be embraced, it is self-evident that in the absence of "the Elected Official's Dilemma" many of today's socio-economic problems would self-resolve themselves. However, society continues to pursue the first option.

\section{Classical Economic Principles and the function of Money in managing public interests.}

As per the prevailing modern economic concepts in use, the quantity of Money (M) plays an important role in the economy.

The prevailing framework states that shortage of $\mathrm{M}$ can slow down or contract economic growth, while excessive amounts can accelerate and even overheat the economic activity. The excessive growth rate of $\mathrm{M}$ will lead to inflation, and shortage of $\mathrm{M}$ will lead to deflation and the subsequent slow down or contraction of the economy. The argument is made that because shortage of $\mathrm{M}$ leads to its appreciation in value, it triggers hording of $\mathrm{M}$, which decreases investments, raises the costs of production, decrease of future profits and leads to economic contraction. Thus, the framework articulates that small inflation is good and hyperinflation is not good, yet much better than deflation.

By this logic, the devaluation of assets through currency debasement appears to be the main driver pushing economic progress. Studies have shown that such devaluation of assets only exacerbates economic hardship. In addition, because of the velocity of propagation of inflation through the economy goes from the top to the bottom, the quantitative easing acts as a mechanism that transfers economic worth from the bottom to the top.

\section{Economic Principles through the prism of function of money and the impact on the behavior of society.}

Modern economic theory describes money as entity that carries three distinct properties:

- Storage of Value 
- Unit of Account

- Medium of Exchange

Money also has an important characteristic called fungibility, which would not be classified as property, but rather as a feature.

Now, let us assess the above economic concept through the prism of the function of money. What impact do the above described economic principles have on the average market participant?

Inflation violates money's property as a storage of value. At the time of economic growth, increased economic activity triggers higher demand for M, and thus camouflages the full detriment of inflation on the money's property as storage of value. At the time of contraction, the impact of inflation becomes more apparent. The interest rate policy, which is in its principle designed to offset loss of value and smooth out economic up-anddown swings, places real value producers at a disadvantage regardless of interest rate direction. Whether interest rates will go up or down, the value producing sector will have losers and winners. However, on the aggregate level there will be more real value taken out of economic producers and transferred to the financial sector due to debasement, or increased financial costs, or both. Various mechanisms that control the propagation speed of newly printed fiat through the economic pipeline make it more difficult to observe its impact over the period of time.

Printing of fiat also disturbs the other two money properties, unit of account and medium of exchange. It is unclear what purpose unit of account serves, if the unit itself has no static value. Imagine an environment where units of measurement for distance, weight, and volume float at will. What type of distorted reality would such a framework of floating units of measurement portray? What type of science and predictive behavior models could one build on the framework of "floating" references? In the absence of a static storage of value and unit of account, the medium of exchange also becomes a concept engendered from the realm of the absurd.

Fungibility is an important feature of money as it enables liquidity and exchange. However, because the printing of fiat changes the underlying properties of money, its fungibility also gets violated. It is well-understood knowledge that a dollar printed in 1970 does not carry the same value as a dollar printed in 2015 . The theory of time value of money account for the change of value over time with the framework of financial calculations, such as FV, NPV, compound and risk free interest, etc. In other words, the dollar printed in 1970 requires a recalculation of the value it stores in order to stay fungible with the dollar of 2015. Just as gasoline with different octane numbers $(93,91$, and 87) store different amounts of energy, the dollar printed in 1970 and the one printed in 2015 have different purchasing powers. One will find it self-evident that gasolines with different octane numbers are not fungible. Yet, the same principle on a more abstract on a non-physical level appears to comfort the majority. Only when the dollar is observed through a timeline and then its value is adjusted through mathematical equations, can one argue that the dollar regains fungibility. However, it is important to point that not all economic transactions are uniformly treated with the same financial adjustment to arrive at the same common denominator of stored value, therefore statistically significant fungibility cannot be claimed even after the adjustments.

This significantly complicates the ability to account and carry forward stored value on an aggregate level. Average market participant's ability to make wise and prudent investment decisions get significantly compromised and even disabled. Even the top intellectual layer struggles with the task of carrying the stored economic value because of the daunting and often impossible task of predicting the outcomes of complexities, controlled by one's will on various levels.

\section{Monetization, Multiplier Effect, and Monotonicity of Economic Functions}

When the unit of economic output gets monetized (converted to the medium of exchange) and funds are deposited into the banking system, the multiplier effect takes place. Because of the banking system of fractional reserves, every deposited dollar is multiplied by factor of 10. In plain language, for every unit of economic output the

$$
7 \text { | P a g e }
$$

Bitcoin Mission $\mathrm{Statement}$. 
banking system creates 10 units of financial claims without impact to the price equilibrium. Once inside of the financial system, the producer of economic output ends up with $1 / 10^{\text {th }}$ of the financial claim on the value of his output, where $9 / 10$ of it is retained by the banking sector through the system of fractional reserves. In economic relations of feudal times, the church was entitled to claim 1/10 of economic output and that was viewed as excessive economic burden. The modern system of fractional reserve brings word "excessive" to the new level.

How is it possible that such leverage of financial claims against real economic outputs does not have dramatic impact on the supply/demand price equilibrium? The most plausible explanation is that the framework of financial regulations and the relations prevents the "leaking" of excessive financial claims directly into demand function. Instead, the empirical evidences suggest that excessive financial claims are channeled into "economic pits" at the level far above of the markets level of marginal propensity to consume (MPS).

Because of the magnitude of the multiplier effect and the centralized system's ability to impose strict controls on how the funds can get channeled or allocated back to the value producing sector, it breaks down the very fundamental assumption of monotonicity of economic functions. That, in turn, puts in question the underlying principles of the free market economy.

\section{The Power of "Economic Pits" and Financial Intermediation}

To gain better understanding of financial intermediation and "economic pits" consider a simple text book example. Imaginary closed economy produces two apples and two oranges. To trade efficiently they require financial claim as medium of exchange (a.k.a. money). To keep things simple financial intermediary assigns four units of financial claim against economic output. The entire economic output is monetized at the rate of 1-to-1 unit of output versus a unit of financial claim (money). The introduction of a medium of exchange seems like reasonable step to make things work better economically. And it really is, unless the control of medium of exchange gets centralized.

PHASE 1

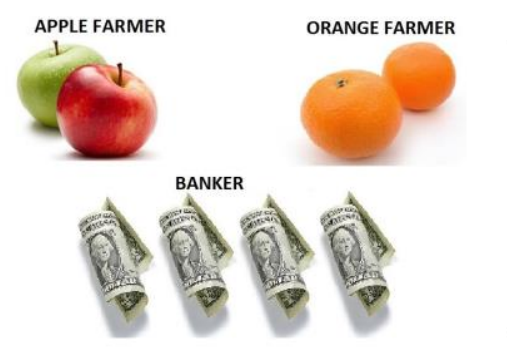

PHASE 2

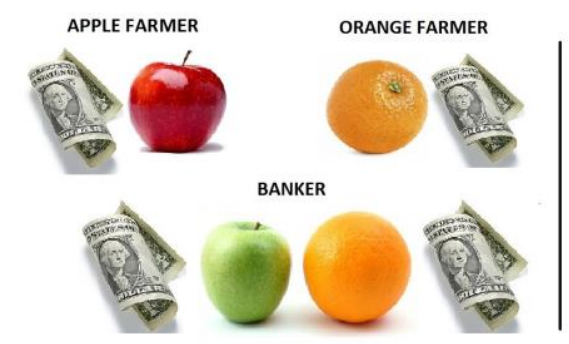

PHASE 3

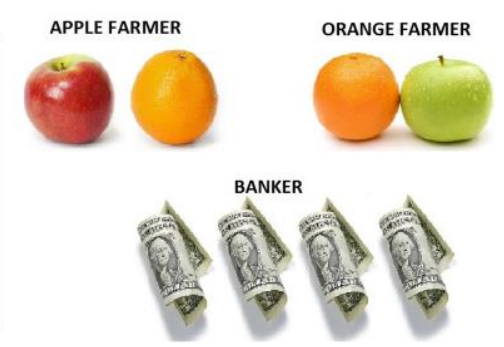

Important to note: this picture illustrates as if the banker facilitates the trade, in addition to being the provider of medium of exchange. In real life, bankers only provides the medium of exchange and separates himself from the actual trade. This important distinction is not represented in this diagram, but will be discussed later.

First let's look at the power of centralized financial intermediation. What this picture illustrates, because of centralized control of medium of exchange and financial intermediation, in phase one the financial intermediary has a claim on entire economic output, in phase two and three financial system has full control of the trade, and what size of fee it can elect to asses for its intermediary services.

- Phase one illustrates that because of the centralized ownership of the claim on the entire economic output, the financial intermediary has the right of first hand to consume as much of economic output as he wishes and transact only remained undesired output, thus having direct impact on exchange.

- Phase two illustrates that the intermediary has full control of the manner of exchange and can influence the price (within the range of profitability margins, of course).

$$
\mathbf{8} \mid \mathrm{P} \text { a g e }
$$


- The full trade cycle illustrates that when a centralized financial intermediary exists, the free market forces become the force of benevolent dictator, and not the force of invisible hand.

Now let's look at the role of "economic pits." The "economic pits" are a dynamic mechanisms or static assets that can trap the impact of newly-printed financial claims for extended period of time, or forever. Economic pits are the tools by which real value is extracted from the value producing sector in exchange for the right to transact via the intermediary.

PHASE 1

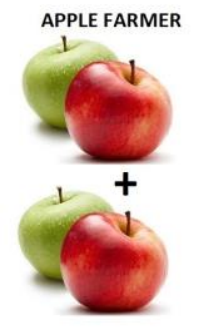

PHASE 2
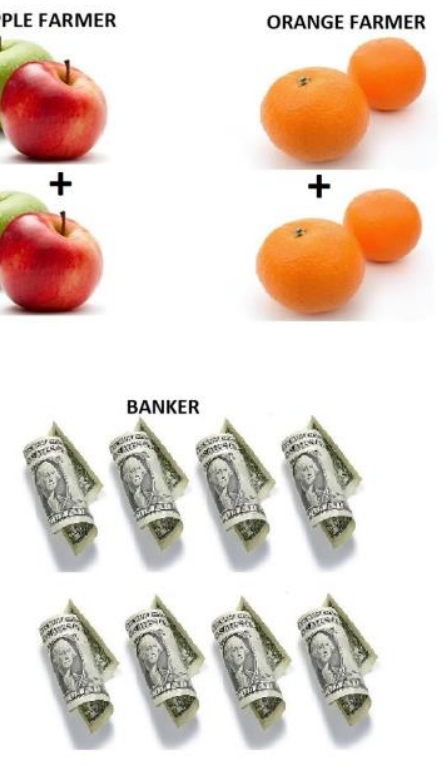
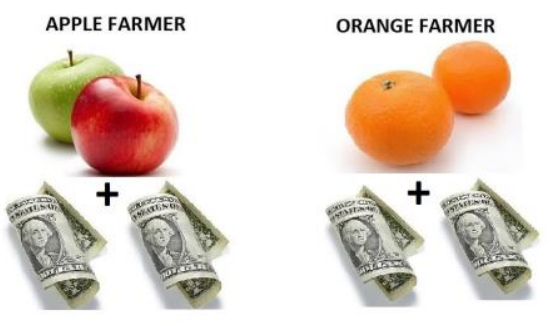

BANKER
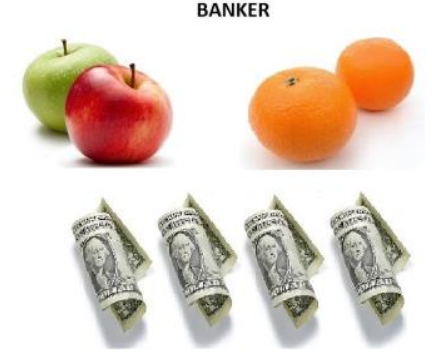

PHASE 3

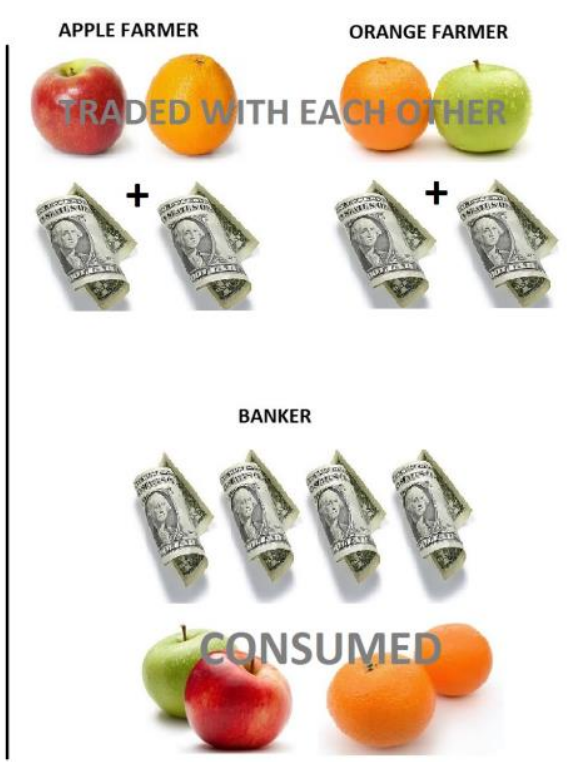

In the above example, in order to saturate the exchange with financial claims, first both farmers have to trade portion of their output with bank, and only then, they can trade with each other. If farmers double their output, the bank will double the number of financial claims to keep price parity constant. (The additional output must be saturated with financial claims.) Both farmers, again, first would have to trade with the bank, exchanging the output for financial claims up to the saturation point, and only then trade with each other. As a result, the financial intermediary can appropriate 50\% share of economic growth in exchange for the right to conduct the trade using his medium of exchange. Thus, the monetization of economic growth (a.k.a. seigniorage) acts as an "economic pit", or dynamic mechanism, that traps newly-printed financial claims and allows the banker to retain units of the real economic output.

It is important to note that the "Elected Official's Dilemma" appears to find a point of reconciliation through the creation, maintenance, and expansion of "economic pits" offered by centralized market intermediary. As long as "economic pits" continue to trap financial claims and extract economic rents, the "Elected Official's Dilemma" is resolved without immediately visible impact on the price parity or economic stability. Yet, the hidden costs of "Elected Official's Dilemma" run high, and in fact, very high.

The combination of the "Elected Official's Dilemma" and the centralized financial intermediary can produce various forms of "economic pits." It is important to note that well performing "economic pits" are required to trap financial claims for an extended time, long enough so that its eventual impact can be blamed on the change of external factors (political, technological, demographic, environmental, etc.). 


\section{Stock Market}

The most intuitive example is a stock market as well as other markets of financial instruments. Initial monetization of underlying assets allows consumption of printed cash without having the impact on pricing parity of economic goods. Growth of stock market valuation is the reflection of assigning more and more of financial claims against real assets. The legislative framework for tax deferred retirement savings serves the dual role of time trap of savings with tax free benefits. The size of this deferred saving pool is the multiple of GDP.

While one can argue that the stock market serves true economic benefits, the economic benefits of the volume of derivatives market has a more questionable value. The financial mechanisms that were initially designed to serve as an insurance instrument for future predictability of prices became converted into a betting parlor for speculators with zero sum game. The argument that the economic value of derivatives market as price maker is shaky for the very least, as the value of bets often surpasses 100 times the value of underlying asset, which makes it beyond inefficient. One could draw an economic analogy with the project in which the cost of planning and budgeting is 100 times more than the actual value of the project.

\section{Dollarization of Foreign Economies}

Another less obvious mechanism of creating new markets for absorption of printed cash is dollarization of foreign economies. Either through political influence, military might, or economic pressure, a selected country is driven to a total or partial replacement of its local currency with currencies of dominant power (USD for example). Various frameworks of financial regulations can be established to complicate the re-entry of foreign dollars back into the home economy, and thus delay its impact on local economy. In addition, specific channels can be created to acquire only specific goods in exchange (i.e., foreign aid).

\section{Through Defining International Laws, Standards, and Trade Agreements}

Another less obvious, yet more powerful, mechanism of creating new markets for absorption of printed cash is accomplished through defining international laws, standards, and trade agreements. The most classical example is the Bretton-Wood Accord. The accord set the stage for USD to become a default currency of world trade, providing an unprecedented opportunity to monetize the economic growth of entire world, and thus set the stage for the U.S. to become world's dominant power, lender of last resort, and provider of world-wide economic and financial stability. The goal of the framework is to require foreign entities to hold indefinitely U.S. denominated cash reserves to satisfy various international laws, standards, and trade agreements.

Creation of new markets provides unprecedented opportunities for absorption of printed cash, and allows a delayed impact of inflation for years. Such economic effect can be skillfully employed as a political instrument during elections with certainty that the electorate has no ability nor mechanisms for critical analysis in order to understand what is actually happening.

\section{Financial Disintermediation - Economics done the right way}

It appears that centralized financial intermediation system is socially unfair and prohibitively expensive. At the time of monetization of economic growth system appropriates more than $50 \%$ of economic value, and the Fed's mandate to maintain a low level of inflation appears to support that. The system of fractional reserve creates ten financial claims for every unit of economic output.

These two forces dramatically dilute the economic benefit retained by the value producing sector once its output is monetized. That is why decentralization of financial services offers a cost effective and more socially fair alternative that is difficult to undermine. The system design disallows monetization of economic growth. This means that the bitcoin will capture and carry forward the rate of economic growth. No longer will the value producing sector need to outrun the inflation in the fear of being diluted by financial sector.

$$
\mathbf{1 0 | P a g e} \quad \text { Bitcoin Mission Statement. }
$$


Decentralization of financial control removes the power of benevolent dictator from the trade, and brings back the market force of the invisible hand. The network of miners more appropriately align itself with the value creating market, which also operates as decentralized network of buyers and sellers. The network effect makes it impossible for financial intermediaries to impact the market trade in the manner of centralized financial intermediary.

\section{Centralized Control as Means of Providing Social Stability}

The social need for centralized control as a means for providing financial stability is also an argument within itself, or argumentum ad logicam. The need for the centralized lender of last resort only exists within a highly centralized system itself. There is no such need within the system that operates on the principles of mesh network. The principles of laissez-faire and spontaneous order are more suitable for the system of mesh network relations under which society thrives and operates.

The centralized control undermines the socio-economic network sustainability and increases its chance of failure thus rising up the cost of insuring against it. The science of topology indicates that hierarchical system built on top of mesh network for the purpose of management severely undermines the resilience of the underlying network and nullifies the benefits it offers. The problems in the management layer will make the entire network susceptible to the problem and will negate the sustainability the network offers otherwise.
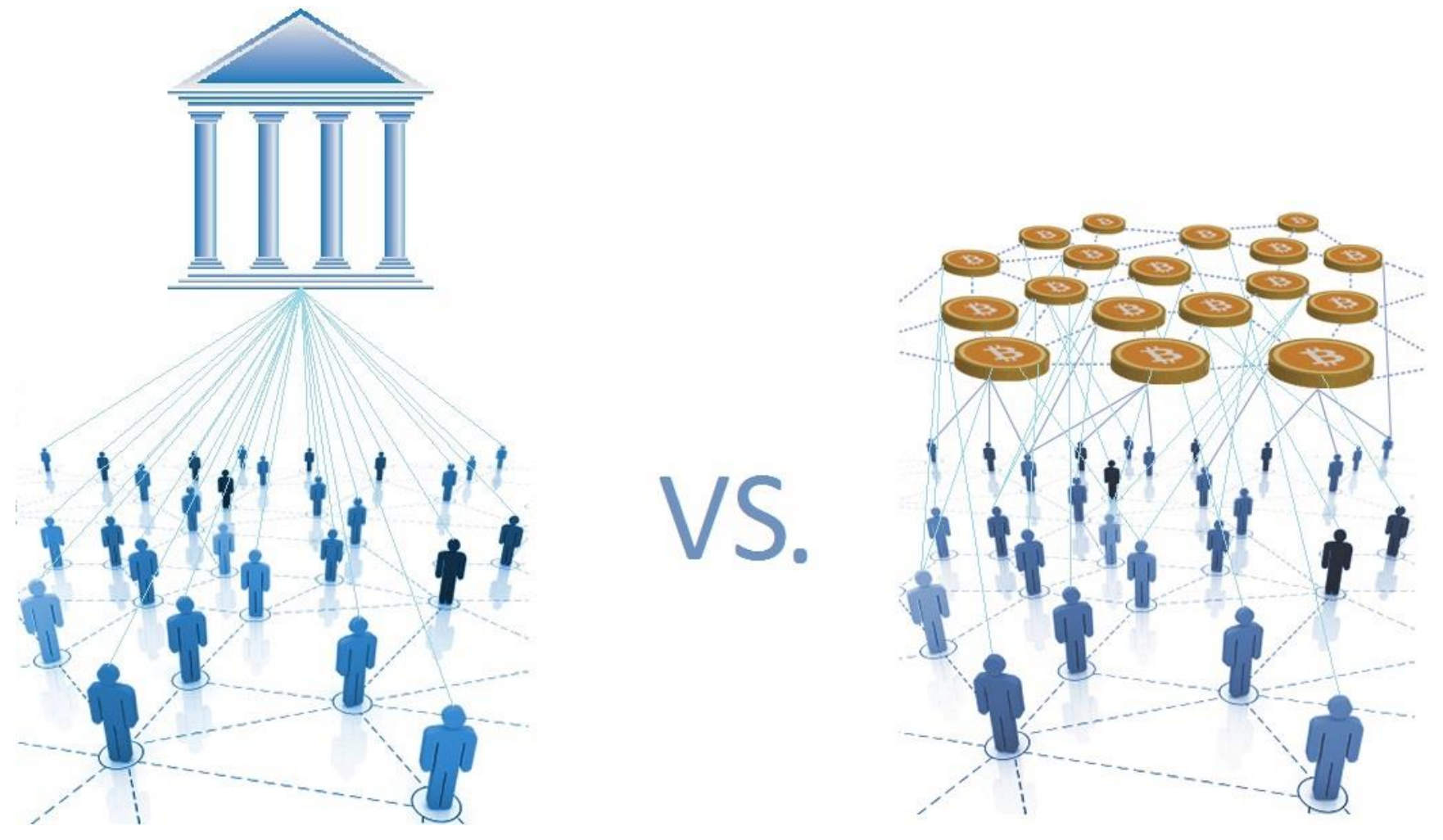

The insurance offered by centralized financial intermediary through mechanism of taxation through inflation is costly. It comes in broad strokes, unevenly distributes the burden, and pushes most of it to the bottom of economic layer, as discussed earlier in the paper.

\section{Decentralization as an Alternative Form of Financial Stability}

The framework offered by Decentralized Autonomous Organization (DAO) makes the network more shock resistant and limits the impact from failed or adversely behaved management layer. The network of Autonomous Agents, automated or not, would perform management activities, without interference with owner's equity and 
ownership. The agent's reach will fall within the owner's needs and agent's jurisdiction. Such configuration will resolve the "Elected Official's Dilemma".

The risk of failure and therefore the cost of insurance against failure of management layer will be dramatically reduced. The same type of insurance can be socially engineered and programmatically enforced by carrying equal impact on all affected members of socio-economic ecosystem. The side chains combined with smart contract can carry exact precision of the impact and guarantee the enforcement of the obligation.

\section{Technological Innovation - Is Crypto-Socialism Next?}

The central bank-based financial system, and more generally, the system with centralized control of the printing and distribution of money, appears to constrain and control the value producing economy by controlling the flow of currencies. Empirical evidence points out that the system extracts significantly more economic benefits than the values it produces, thus engaging in rent-seeking behavior. When economic growth slows down, the impact of rent-seeking becomes even more detrimental. When combined with political forces, it can take even more aggressive forms, such as the destruction of value for the purpose of creating the need for its services.

The most recent tech sector innovations, such as smart contracts and crypto-currencies are poised to disrupt the existing system.

Today, the fundamental value proposition of centralized systems is the offer of trust and reliability. The importance of it is difficult to overestimate, as the two most important functions of the government are enforcement of contracts and property rights. Even though the system is costly and inefficient, it was the only option available until most recently.

The technological innovations of crypto-currencies and smart contracts provide an effective alternative programmable trust in the form of a trustless decentralized network of computer nodes. New technology combines into one framework the mechanisms of cryptology with the principles of distributed computing. This makes it possible to create trustless escrow accounts without intermediaries, pre-programmed and self-enforceable contracts with the desired mix of transparency and anonymity, and a ledger of records history which cannot be changed or altered. Many of the roles of government and other centralized authorities are in danger of being automated. The "Elected official's Dilemma" will be resolved.

Crypto-currencies carry the promise of replacing country specific currencies. This removes the ability to gain competitive advantage by a specific country through the beggar thy neighbor policy, typically coming at the expense of its currency debasement.

The (crypto-currency) network breaks down the banking pyramid of propagating fiat via economic channels. Thus it eliminates the competitive advantage of having access to newly printed cash, receiving disproportionate benefits from multiplier effect and fractional reserve system, which would then return system back to one of value creating completion.

The ability to store and transact any value outside of a traditional financial system is one of the key values of the system. This means that the enforcement of capital controls, or other decisions designed to control capital flow can be circumvented. This creates the dilemma where the power of decision making exists, but the power of enforcing it does not. With the absence of the power of enforcement, the credibility of the authorities cripples. The new tools created by technological advancements will trigger and force the changes of the socio-economic framework, just like it happened during transition from feudalism to capitalism. 


\section{Conclusion}

It appears that we are standing at an historical moment, when new technological advancements are poised to disrupt the existing system of socio-economic relations.

Similar to the end of feudal times, today's technological advancements brought to light that decentralization of governance and finance offers more socially just and, at the same time, a more economically efficient form of coexistence. Profitability driven, centralized forms of governance inundated with rent seeking schemes of all kinds will become the system of the past. The framework of Decentralized Autonomous Enterprises (DAE) empowered by smart contracts and the crypto-currencies, offers our future to replace today's unhealthy competition for survival of capital with the collaboration for value creation. The collaboration for value creation offers to build a more stable, more socially just, and less judicially-driven economic environment, where the act of passion will have a more direct path to the act of the innovation.

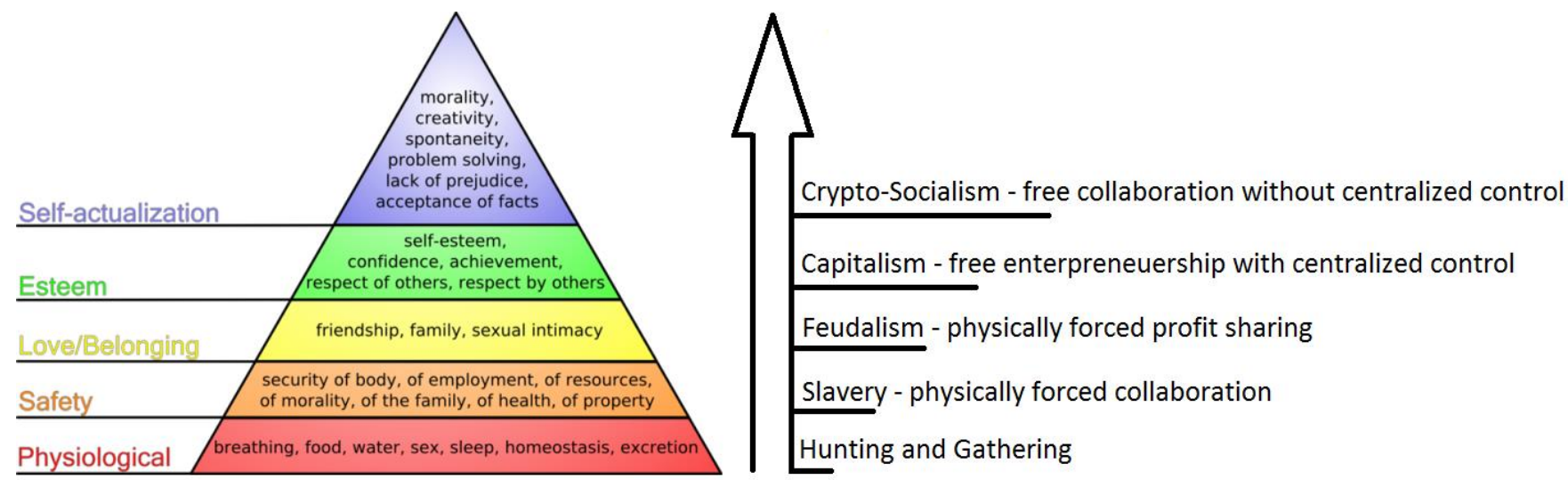

Yet, just like in feudal times, for the society to attain full potential of technological advancements and to reach qualitatively different level of productivity from collaborative environment, the labor is required to reach new higher levels on the Maslow's pyramid of the hierarchical needs. High moral standards, lack of prejudice, creativity, focus on problem solving, and acceptance of facts must become integral parts of collaborative relationships and the employee-employer obligations ${ }^{\mathrm{ix}}$. Over time this will transform the fabric of the society. Human kind will ascend to new heights and the historical period where the laws of accumulating the capital were the main drivers of formation of the system of values will become the pages in the history books.

This work was inspired by:

https://vimeo.com/111576518

Donate with Bitcoins to support this research 


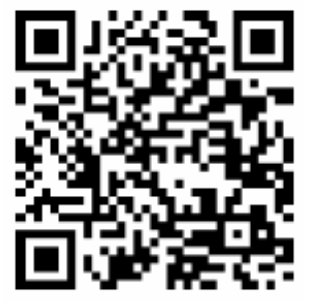

15wtcbR3aypU1ZUNXpjocdwK4MqAfmjdPC

\section{Acknowledgements and Contributions}

The author thanks Simon Mogilevsky for extensive collaboration on this work. Simon played key role in contributing to the concepts related to social implications of Blockchain technologies. Simon was instrumental in editing and flushing out key ideas. He also helped to identify historical and philosophical references.

The author also would like to thank longtime mentor Ron Cole, and longtime colleague Dmitry Nesterenko. Ron and Dmitry provided assistance with validation of technical concepts and architectural ideas.

The author also would like to thank his son, Benjamin Kosten, for helping with illustrations for this document.

\section{References}

[1] Rickards, James. Currency Wars: The Making of the next Global Crisis. London: Portfolio, 2012. Print.

[2] Piketty, Thomas, and Arthur Goldhammer. Capital in the Twenty-first Century. Cambridge Massachusetts: Belknap of Harvard UP, 2014. Print.

[3] Davidson, Steven, Martin Harmer, and Anthony Marshall. "The New Age of Ecosystems." The New Age of Ecosystems. IBM Institute for Business Value, 16 July 2015. Web. 29 Oct. 2015. <http://www-

01.ibm.com/common/ssi/cgi-bin/ssialias?htmlfid=GBE03617USEN\&appname=skmwww>.

[4] Vitali, Stefania, James B. Glattfelder, and Stefano Battiston. "The Network of Global Corporate Control." (n.d.): n. pag. 19 Sept. 2011. Web. 29 Oct. 2015. <http://arxiv.org/pdf/1107.5728v2.pdf>.

[5] "America's Top Fears 2015." Wilkinson College of Arts Humanities and Social Sciences Americas Top Fears 2015 Comments. N.p., n.d. Web. 29 Oct. 2015. <https://blogs.chapman.edu/wilkinson/2015/10/13/americas-topfears-2015/>.

[6] Nakamoto, Satoshi. "Bitcoin: A Peer-to-Peer Electronic Cash System." Legitimate Applications of Peer-toPeer Networks: 1-9. Web. 29 Oct. 2015. <https://bitcoin.org/bitcoin.pdf>.

[7] Howard, Patrick, Dorit Nevo, and Pat Toole. "Small Worlds: The Social Approach to Software Delivery." Small Worlds: The Social Approach to Software Delivery. IBM Institute for Business Value, 16 Oct. 2012. Web. 29 Oct. 2015. <http://www-01.ibm.com/common/ssi/cgibin/ssialias?infotype $=$ PM\&subtype $=$ XB \&htmlfid=GBE03499USEN $>$.

[8] Pureswaran Veena, Sanjay Panikkar, Sumabala Nair, and Paul Brody. "Empowering the Edge - Practical Insights on a Decentralized Internet of Things." Empowering the Edge - Practical Insights on a Decentralized Internet of Things. IBM Institute for Business Value, 17 Apr. 2015. Web. 29 Oct. 2015. <http://www01.ibm.com/common/ssi/cgi-bin/ssialias?infotype=PM\&subtype=XB\&htmlfid=GBE03662USEN\#loaded $>$. 
[9] James Manyika, Michael Chui, Peter Bisson, Jonathan Woetzel, Richard Dobbs, Jaques Bughin, and Dan Ahron. "The Internet of Things: Mapping the Value Beyond the Hype.” McKinsey Global Institute, June 2015. Web. 29 Oct. 2015

[10] Victoria Espinel, Derek O’Halloran, Erik Brynjolfsson, Domhnall O’Sullivan, et.al. Survey Report: “Deep Shift: Technology Tipping Points and Societal Impact." World Economic Forum, September 2015. Web. 29. Oct. 2015 〈http://www.weforum.org/reports/deep-shift-technology-tipping-points-and-societal-impact>.

[11] Luigi Zingales. "When business and government are bedfellows." The Economist, August 23, 2012. Web. 29. Oct. 2015. < http://www.economist.com/blogs/prospero/2012/08/quick-study-luigi-zingales-crony-capitalism>

\section{Annotations}

i “Let me issue and control a nation's money and I care not who writes the laws.” Mayer Amschel Rothschild (1744-1812), founder of the House of Rothschild.

ii "The New Age of Crony Capitalism." The Economist. The Economist Newspaper, 15 Mar. 2014. Web. 29 Oct. 2015. <http://www.economist.com/news/leaders/21598996-political-connections-have-made-many-people-hugely-rich-recentyears-crony-capitalism-may>. Luigi Zingales. "When business and government are bedfellows." The Economist, August 23, 2012. Web. 29. Oct. 2015. < http://www.economist.com/blogs/prospero/2012/08/quick-study-luigi-zingales-cronycapitalism>

iii It is also consistent with Laisez-Faire - an economic system in which transactions between private parties are free from government interference such as regulations, privileges, tariffs, and subsidies. Wikipedia:

<https://en.wikipedia.org/wiki/Laissez-faire>

iv Overstock CEO Patrick Byrne announces new financial technology innovation https://www.youtube.com/watch?v=suhYcwXwV2o

v In the IBM's white paper called "The New Age of Ecosystems" the authors describe that within the Ecosystems the orchestration is the form of value creation that translates to revenue generation stream. The financial services organizations most likely to operate the "Lion's pride" type of ecosystem, which carries highest level of complexity and orchestration.

vi Thomas Piketty in his book Capitalism in $21^{\text {st }}$ Century, illustrates that over-concentration of capital negatively influences economic growth.

vii Maslow's pyramid of hierarchical needs. Source: <https://en.wikipedia.org/wiki/Abraham_Maslow>

viii Milton Friedman speech at CATO Institute: "There's no such thing as a free lunch (CATO). https://www.youtube.com/watch?v=AcOviVhRb9g

ix “..The pressure for speed and performance in today's tough markets is relentless, a point readily appreciated by business executives and CIOs. ... To deliver incremental improvements of standard practices in these markets would not suffice. What is needed is radical new thinking about traditional delivery models that moves from the hierarchical, closed, and resourcefocused model to an open environment that embraces community, social recognition, transparency and outcomes." IBM Institute for Business Value: "Small World: The Social Approach to Software Delivery” http://www01.ibm.com/common/ssi/cgi-bin/ssialias?infotype=PM\&subtype=XB\&htmlfid=GBE03499USEN 